\title{
Characterization of the Intestinal Microbiota and Metabolites of Broiler Breeders with Different Egg Laying Rate
}

\author{
Zengqiao Yang \\ Pietro Celi \\ Keying Zhang \\ Sichuan Agricultural University \\ Xuemei Ding \\ Sichuan Agricultural University \\ Shiping Bai \\ Sichuan Agricultural University \\ Qiufeng Zeng \\ Sichuan Agricultural University \\ Xiangbing Mao \\ Sichuan Agricultural University \\ Bing Feng \\ Sichuan Agricultural University
}

Institute of Animal Nutrition, Sichuan Agricultural University https://orcid.org/0000-0001-5725-2311

Jianping Wang ( $\nabla$ wangjianping@sicau.edu.cn )

Faculty of Veterinary and Agricultural Sciences, The University of Melbourne; DSM Nutritional Products, Animal Nutrition and Health, Columbia

\section{Research article}

Keywords: Broiler breeder, microbiota, metabolomics, gastrointestinal functionality

Posted Date: August 21st, 2019

DOI: https://doi.org/10.21203/rs.2.13269/v1

License: (9) (7) This work is licensed under a Creative Commons Attribution 4.0 International License. Read Full License 


\section{Abstract}

Background

The aim of the present study was to determine differences in the intestinal microbiota and metabolites of broiler breeders with different egg laying rate; and its possible relationships between intestinal microbiota and intestinal metabolites were also explored.

Methods

A total of $200 \mathrm{AA}+$ parent broiler breeders (41-week-old) were separated into two groups according to their different egg laying rate: average reproductive group (AR: $77.26 \% \pm 0.88 \%$ ) and high reproductive group (HR: $86.67 \% \pm 0.75 \%$ ), with 10 replicates and 10 birds each 42 -days study.

Results

Feed conversion ratio (FCR), ovary cell apoptosis rate (ApoCR) and abdominal fat pad weight percentage were lower $(p<0.05)$, while the hatchability of qualified egg rate $(\mathrm{HQR})$ was higher $(\mathrm{p}<0.05)$ in $\mathrm{HR}$ group than that in AR group. At phylum level, Firmicutes and Proteobacteria were the dominant bacteria in small intestines, while Bacteroidetes was dominant bacteria in cecum. At genus level, Lactobacillus was dominant in small intestines while Bacteroides were dominant in cecum. In HR Phascolarctobacterium were lower $(p<0.05)$ in ileum. A positive correlation was observed between Actinobacteria in the small intestines and ApoCR $(r=0.34 \& p<0.05)$. A positive correlation was observed between FCR and Spirochaetes in cecum $(r=0.54 \& p<0.05)$. The metabolomics analysis on ileal digesta content revealed a higher concentration of Octadecanoic acid, 9,12-0ctadecadienoic acid, 11-trans-Octadecenoic acid, d-Ribose and Inositol in HR broiler breeders. Moreover, inositol was enriched in "Phosphatidylinositol signaling system", "Inositol phosphate metabolism", "Ascorbate and aldarate metabolism", "Galactose metabolism", "ABC transporters", and Octadecanoic acid was enriched in "Fatty acid biosynthesis", "Biosynthesis of unsaturated fatty acids".

Conclusions

Our results suggest that glycerol, inositol modulate energy partitioning in fat metabolism to influence reproductive performances. Microbiota, such as Actinobacteria (phylum), Spirochaetes (phylum), and Phascolarctobacterium (genus) may have negative relationship with broiler breeders' reproductive performances.

\section{Background}

Poultry is one of the most important sources of protein (meat and eggs) for human nutrition[1]. Over the past years, a significant improvement in poultry production has resulted in extremely high level of efficiency in both broiler chickens and layer hens, with birds reaching $3 \mathrm{~kg}$ in body weight at 40 days of age and hens laying 500 eggs in 100 weeks [2].

Accumulating evidences suggest that the intestinal microbiota could affect the poultry production[3]. The microbiota is defined as the microbial community, including commensal, symbiotic and pathogenic microorganisms [4] which could interact with the host, resulting in the influence of metabolism, immunity and even behavior [5]. A normal and stable microbiota play a pivotal role in maintaining optimal gastrointestinal functionality, animal health, welfare and production performances [6].

It has been reported that the microbiota can modulate the host's digestive[7-10], endocrine [5], immune[11, 12] and nervous systems function [13]. The gastrointestinal (GIT) microbiota contributes to the regulation of fat deposition [14] which in poultry seems to be independent of host genetics [15]. These observations are not surprising considering that microbial metabolites such as short-chain fatty acids have been implicated in the modulation of energy metabolism[16]. Furthermore the microbiota can improve feed conversion efficiency [17] as a consequence of their ability to synthetize beneficial nutrients such as vitamins [18-20] and by improving the energy harvest from the diet, resulting in improved growth performances. Moreover, in addition to the wellknown links between the GIT microbiota and the neuroendocrine function of the gut [21], it has been shown that dysbiosis of the GIT microbiota can result in the activation of the immune system which in turn raise serum insulin levels and androgen production disrupting ovarian function [22]. Indeed, in humans, polycystic ovary syndrome (PCOS) is associated with altered insulin sensitivity and hormonal imbalance [23]. Whether the GIT microbiota is involved in the regulation of ovarian activity in poultry is still not known.

In this study, we intended to explore the possible relationships between the GIT microbiota, intestinal metabolites and ovarian function in broiler breeders with different egg laying rate. The results will provide clarity of understanding of the effect of the GIT microbiota on broiler breeders' gastrointestinal functionality.

\section{Methods}

\section{Birds, experimental design and Management}

A total of $200 \mathrm{AA}+$ parent broiler breeders (41-week-old) bought from the Sichuan Yuguan Agricultural Co., Ltd were divided into two separate groups, according to their different egg production rate (EPR; AR: $78.57 \% \pm 0.00 \%$ vs. HR: $95.79 \% \pm 0.43 \%$ ). For each of the two groups 10 replicates of 10 birds each were enrolled in a 42-days trial. Broiler breeders were subjected to artificial insemination every 4 days. All birds were fed restrictedly with the same composition of diet at 162 gram per bird; environmental temperature was maintained at $23^{\circ} \mathrm{C}$; the daily lighting schedule was $16 \mathrm{~h}$ light and $8 \mathrm{~h}$ dark. Birds had ad libitum access to water. 


\section{Sample Collection and Measurements}

Egg production, broiler breeder mortality, qualified hatching egg production and feed consumption were recorded daily. Hatching performance was recorded at day 42. At end of the study (day 42), birds were sacrificed by cervical dislocation and the intestines were removed for the measurement of duodenum (Duo), jejunum (Jej), ileum (Ile), cecum (Cec) weight and length. The content of the duodenum, jejunum, ileum and cecum was immediately transferred into $1.5 \mathrm{ml}$ sterile centrifuge tubes for microbiota and metabolomics analysis. The ovaries were collected and placed into $4 \%$ paraformaldehyde $(\mathrm{pH}=7.2)$ for cell apoptosis analysis.

\section{Follicle Apoptosis by TUNEL Method}

Sections were histochemically stained using the TUNEL technique by an in situ apoptosis detection kit (Roche, Switzerland; [24]. The follicle section of ovary was aseptically removed and placed immediately into a solution of 3-ethoxy-3-aminopropyl silane (Zhongshan Golden Bridge Biotechnology Co., Ltd. Beijing, China). Set into oven to $60^{\circ} \mathrm{C}$ for $60 \mathrm{~min}$. Dewaxing and hydration. After an incubation with proteinase $\mathrm{K}$ (Boehringer Mannheim, Germany), rinse thrice with PBS. With $50 \mu \mathrm{L}$ TUNEL in the reaction mixture specimens, with slide in the dark wet box in response to $37^{\circ} \mathrm{C}$ for $1 \mathrm{~h}$. Rinse thrice with PBS. Add $50 \mu \mathrm{L}$ (converter- POD) in liquid samples, or sealing membrane reaction $37^{\circ} \mathrm{C}$ in the dark wet box with glass for 30 min. Rinse thrice with PBS. $50-100 \mu \mathrm{L}$ DAB chromogenic agent, reaction of $25^{\circ} \mathrm{C}, 10 \mathrm{~min}$. Rinse thrice with PBS Hematoxylin staining, rinse water after a few seconds; alcohol dehydration, xylene transparent, neutral balata. Using BA200Digital (Mike Audi Industrial Group Co., Ltd.) to image acquisition. Apoptotic color is brown yellow, and negative expression is blue with white background.

\section{DNA Extraction and Microbiota Analysis}

Total microbial genomic DNA was extracted from the chyme of duodenum, jejunum, ileum and cecum, using the TIANamp Bacteria DNA isolation kit (DP30202, Tiangen, Beijing, China) according to the manufacturer's instructions. 16S rRNA genes of distinct regions (16S V4) were amplified used the specific primers 515F (5'-GTTTCGGT GCCAGCMGCCGCGGTAA-3') and 806R (5'-GCCAA TGGACTACHVGGGTWTCTAAT-3') with the barcode. All PCR reactions were carried out with Phusion ${ }^{\circledR}$ High-Fidelity PCR Master Mix (New England Biolabs). PCR products, a bright main strip between $400-450$ bp, were mixed in equal density ratios for purification with Qiagen Gel Extraction Kit (Qiagen, Germany). Sequencing libraries were generated via the TruSeq ${ }^{\circledR} D N A$ PCR-Free Sample Preparation Kit (Illumina, USA) following manufacturer's recommendations, index codes were added. Finally, the library was sequenced on an IlluminaHiSeq2500 platform and 250 bp paired-end reads were generated. Splicing sequences were using FLASH (V1.2.7) to assemble[25], and then quality filtration was using QIIME (V1.7.0) [26] to finish. Chimera tags were removed using UCHIME algorithm [27]. Sequence analysis were performed via Uparse software (Uparse v7.0.1001) [28].

The resulting sequences with $\geq 97 \%$ similarity were clustered into OTUs. The representative sequences of each OTU were aligned to the Greengene Database [29] based on the RDP classifier algorithm (Version 2.2 [30] to annotate taxonomic information. Alpha diversity metrics (Observed-species, Chao1, Shannon, Simpson, ACE, and Good-coverage) were calculated with QIIME (Version 1.7.0) and displayed with R software (Version 2.15.3). Beta diversity metrics (weighted UniFrac and unweighted UniFrac) were calculated with QIIME software (Version 1.7.0). PCoA analysis based on weight-unifrac was conducted with the WGCNA package, stat packages, and the ggplot2 package in R software (Version 2.15.3). Spearman analysis was conducted with the diversity/alpha diversity index package and the environmental factors package in R software (Version 2.15.3; [31]. The sequence data reported in this study have been deposited in the NCBI database (Accession No. SRP132757).

\section{Metabolites Analysis and KEGG Pathways}

Sample pretreatment was described in detail in the supporting information (Supplementary Methods, Additional File 1). The derivatized samples were analyzed by GC/MS (Agilent 6890A/ 5973C, Agilent Technologies, Santa Clara, CA, USA). The detail parameters were described under Supplementary Methods (Additional File 1).

The original GC/MS data were converted into files in netCDF format [32] and subsequently preprocessed, including the identification, filtration, and alignment of peaks by XCMS software (www.bioconductor.org). Finally, a data matrix of information, including mass-to-charge ratios ( $\mathrm{m} / \mathrm{z}$ ), retention times, and peak intensities, was obtained. Identification of metabolites was performed using the AMIDS system (Automated Mass Spectral Deconvolution and Identification System) by searching the National Institute of Standards and Technology library (http://srdata.nist.gov/gateway/) [33].

The resultant GC-MS data matrix were imported into the MetaX software package (http://metax.genomics.cn) for multivariate analysis, including principal component analysis (PCA) and partial least squares discriminant analysis (PLS-DA). PCA was utilized to visualize global clustering and display differences in metabolic profiles between samples. To achieve the maximum separation between samples, PLS-DA was used to identify differential metabolites that explained the separation between groups, missing values were imputed using a k-Nearest Neighbor (KNN) method [34]. The model quality was evaluated using the R2X, R2Y, and Q2 parameters. The R2X and R2Y parameters, which represent the fractions of explained X-variation and Y-variation, respectively, can be used to evaluate the quality of the model. The Q2 parameter represents the predictive ability of the model. In general, the model is acceptable when the values of $R^{2} X, R^{2} Y$, and $Q^{2}$ are greater than 0.5 [35]. In addition to cross-validation, the PLS-DA models were verified via 200 repeated permutation tests.

As described above, PLS-DA was employed to identify differential metabolites between groups. Furthermore, variable importance in the projection (VIP) values in the PLS-DA model were used to rank the metabolites based on their importance indiscriminating between groups. Metabolites with the highest VIP values are the most powerful group discriminators. Traditionally, VIP values $>1$ are significant. In this study, metabolites with VIP values (VIP > 1.0) in the PLS-DA 
model, significance $(p<0.05)$ in Student's $t$-test $(\mathrm{R}$ package) and fold change $<0.83$ or $>1.2$ were selected as differential metabolites. Then, receiver operating characteristic (ROC) curves analysis was performed (R package pROC), and the areas under the curves (AUCs) were calculated to determine the diagnostic value of these differential metabolites [36]. The discriminatory power of the differential metabolites was ranked and visualized using heat maps [36]. Metabolic pathways were obtained for these identified differential metabolites from the KEGG (Kyoto Encyclopedia of Genes and Genomes) database (http://www.genome.jp/kegg).

\section{Statistical Analysis}

Data was analyzed by independent-sample T-test in the SPSS version 25.0 statistical software package (IBM ${ }^{\circledR}$ SPSS ${ }^{\circledR}$ Statistics, New York, USA), differences among treatments were considered significant at $p<0.05$. Alpha indexes were analyzed by Wilcox rank sum test, differences among treatments were considered significant at $p<0.05$. Adonis test was based on Bray-Curtis distance, differences among treatments were considered significant at $p<0.05$.

\section{Results}

\section{Reproductive Performance}

Average daily feed intake (ADFI) in both HR and AR birds; similarly, no differences in egg weight, qualified and unqualified egg rates were observed between the two groups. Feed conversion ratio (FCR), however, was lower in the HR birds $(p<0.05)$. As expected, the hatchability of qualified egg rate $(\mathrm{HQR})$ was higher in the HR group $(p<0.05)$ (Table 1).

\section{Digestive Organs}

Compared to the AR groups, birds in the HR group presented a lower abdominal fat content $(p<0.05)$, however no differences were observed for chicken weight, relative weight of crop, proventriculus, gizzard, intestines (duodenum, jejunum, ileum, cecum) (Table 2) and length of intestines (Supplementary Table 1, Additional File 2).

\section{Ovary cell apoptosis}

Ovary cell apoptosis rate (ApoCR) in the ovaries of the HR birds was lower than to that observed in the AR group $(p<0.05)($ Fig 1$)$.

\section{Summary of High-Throughput Sequencing and Alpha Diversity}

The present study obtained a total of 5,328,583 high quality 16 S rRNA gene sequences from duodenum $(1,253,578)$, jejunum $(1,320,806)$, ileum $(1,347,555)$, cecum $(1,406,644)$, with an average of 83,259 sequences per sample and a range of 67,290 to 95,053 . A total of 36,679 0TUs were identified at $97 \%$ sequence identity. The Chao1 and ACE indexes were lower in duodenum and ileum of HR $(p<0.05)$ (Fig $2 \mathrm{a}, \mathrm{b})$ and Shannon index was lower in ileum of HR ( $p<0.05)$ (Fig $2 \mathrm{c}$ ). The Venn and Flower diagrams were used to describe common and unique OTUs between goups. In the duodenum, jejunum, ileum and cecum of the AR and HR birds, we observed, respectively, 713, 595756 and 1046 common OTUs (Fig 3).

\section{Taxonomic Composition of GIT microbiota}

A total top 10 phyla and top 10 genera were based on the identified OTUs. At phylum level, Firmicutes, Proteobacteria in duodenum, Firmicutes, Cyanobacteria in jejunum and ileum, Firmicutes, Bacteroidetes in cecum were the predominant phyla (Fig 4, a) (Table 3-1). At genus level, Lactobacillus, Unidentified_Chloroplast, Helicobacter, Bacteroides and Phyllobacterium in duodenum, jejumum and ileum, Lactobacillus, Fusobacterium, Bacteroides and Rikenellaceae in cecum were the predominant genera (Fig 4, b) (Table 3-2). With the T-test, in ileum Pyhllobacterium and Phascolarctobacterium were lower ( $p$ $<0.05$ ) (Fig 4, c; Supplementary Table 2, Additional File 2) in HR, in cecum Ruminiclostridium_5 was lower $(p<0.05)$ and Precotellaceae_UCG-001 was higher $(p<0.05)$ (Fig 4, d; Supplementary Table 3, Additional File 2) in HR.

The principal coordinate analysis (PCoA) based on weighted unifrac distance was applied to examine differences in taxonomic community composition and structure in the duodenum, jejunum, ileum and cecum. The PCoA analysis indicates that the bacterial community composition of the duodenum, jejunum, ileum and cecum of the HR birds can be separated from that of the AR group (Fig 5), however this separation did not reach significant difference (Table 4).

Spearman correlation analysis was employed to explore correlations between microbiota richness and performance parameters (EPR, FCR, HQR and ApoCR) measured in this study. At phylum level, Actinobacteria in the small intestines were positively correlated with ApoCR. Euryarchaeota in the small intestines were negatively correlated with EPR and HQR and positively correlated with FCR. At genus level, Phyllobacterium, Romboutsia, Megamonas, Coprococcus_ 1 in the small intestines were negatively correlated with EPR; Phyllobacterium in the small intestines were positively correlated with FCR (Table 5-1). At phylum level, Spirochaetes in the cecum was positive correlated with FCR while Planctomycetes in the cecum was negatively correlated with HQR. At genus level, Sphaerochaeta in the cecum was negatively correlated with EPR (Table 5-2).

Metabolites and KEGG Pathways 
A total of 71 metabolites were identified in both ileal and caecal samples. Ileal metabolites presented a higher level of expression than the caecal ones (Fig 6 , a). In the ileum Octadecanoic acid, 9,12-Octadecadienoic acid, 11-trans-Octadecenoic acid, d-Ribose and inositol were expressed at higher level in the HR birds, according to their VIP values in the PLS-DA model (VIP $>1)$ and p-value from Student's t-test $(p<0.05)$ : (Fig 6, b; Table 6). In the cecum, we observed that inositol was lower in the HR birds (Table 6). A ROC analysis was carried out to determine the ability of the identified ileal metabolites to discriminate between the AR and HR groups. The heatmap (Fig 6, c) reports the ileal metabolites ranked in order of their AUC values, and indicated that the five metabolites were effective in discriminating between the HR and AR birds. The KEGG pathway database was utilized to analyze the metabolic pathways relating to the five metabolites identified in the ileum. We observed that inositol was enriched in the "Phosphatidylinositol signaling system", "Inositol phosphate metabolism", "Ascorbate and aldarate metabolism", "Galactose metabolism", "ABC transporters", while octadecanoic acid was enriched in the "Fatty acid biosynthesis", "Biosynthesis of unsaturated fatty acids" pathways (Fig 6, d).

\section{Discussion}

\section{Reproductive performances}

The main function of the GIT is to digest feed and absorb nutrients. In the small intestine (duodenum, jejunum and ileum), the host absorbs mostly the nutrients of dietary origin [37], while in the cecum, the host absorbs nutrients that product by microbial fermentation [38, 39]. It is well accepted that productive and reproductive performances are influenced by absorption and utilization of nutrients in poultry [40, 41]. In the present study, even though both AR and HR birds were fed the same diet, we observed that abdominal fat was lower in the HR birds, but both body and organ weight was not different from that of AR birds (Table 2). Moreover, FCR was lower in HR birds (Table 1), which suggests that energy and nutrients were used for production purposes rather than being diverted to abdominal fat depots as observed in the HR birds. It has been reported that changes in ovarian function are accompanied by increased abdominal adiposity [42-46] and that body fat is negatively correlated with fertility [47]. These observations support our findings that ApoCR was higher in the AR birds (Fig 1).

\section{Metabolites}

In the present study, with the KEGG enrichment pathway analysis, we found that in "Fatty acid biosynthesis" and "Biosynthesis of unsaturated fatty acids" pathways, hexadecanoic acid (palmitic acid) was lower while octadecanoic acid (stearic acid) was higher in the HR birds (Supplementary Fig 1, Fig 2, Additional File 2). In agreement with our observations are the finding of Xie et al (2012) where broiler hens had increased abdominal fat pad weight and reduced egg production. it has been observed that high concentrations of palmitic acid can be toxic to granulosa cells [48]. Palmitic acid is a saturated fatty acid that can induce cellular apoptosis and exert cytotoxic effect as it is a precursor of the complex lipid ceramide, which has been reported to induce apoptosis in granulosa cells of hens [49]. Palmitic acid can also induce cellular apoptosis through a ceramide-independent pathway [50]. Finally, palmitic acid and stearic acid could induce apoptosis in human ovarian granulosa cells [51]. In our study we observed higher stearic acid expression in the HR birds, however in light of the lower ApoCR and levels of palmitic acid observed in this group, it is likely that the higher stearic acid expression was not sufficient to exert any negative effect on ovarian function in the HR broiler breeders.

We observed that in the "Inositol phosphate metabolism" and "Galactose metabolism" pathways, glycerol was lower while inositol (D-myo-inositol) was higher in the HR birds (Supplementary Fig 3, Fig 4, Additional File 2). Glycerol can be converted into glycerol-3-phosphate and glyceric acid via glycolysis to supply energy [52] which probably was diverted to the abdominal fat depots in the AR birds. In the "Inositol phosphate metabolism" pathway, phosphatidyl-1D-myoinositol, an intermediate in inositol phosphate metabolism, was also indirectly linked to the "Glycerophospholipid metabolism", which plays an important role in fat metabolism [53]. Although in present study, we observed that inositol was lower in the cecum of the HR birds (Table 6), the overall expression of inositol in the GIT of HR birds was higher than that observed in the AR birds.

Overall, our findings suggest that intestinal metabolites play a significant role in fat metabolism though by modulating energy partitioning which can subsequently influence reproductive performances.

\section{Microbiota}

The nutritional requirements of the gastrointestinal microbiota are species-dependent as bacteria need different dietary substrates for their growth and metabolic activity[39]. Therefore it is obvious that in the gastrointestinal there is a resources competition between the microbiota and the host. In present study, we observed that the duodenum and jejunum microbiota of AR birds has more richness than that of the HR ones (Fig 2 a, b), and the ileum microbiota was more diverse in the AR birds than in the HR one (Fig $2 \mathrm{c}$ ). The above mentioned higher diversity and richness of bacteria in the AR birds could have resulted in an increased nutrients competition with the host and the microbiota in the small intestines; the higher FCR observed in the AR birds could support this hypothesis. In present study, Firmicutes and Proteobacteria were the dominant phyla in the small intestines while Bacteroidetes was the dominant bacteria in the cecum. Lactobacillus was thedominant genus in the small intestines while Bacteroides was the dominant genus in the cecum. Similar observations have been made in broiler chickens and laying hens [54,55]. Diet is a well known factor that can influence the microbiota composition and metabolic activity [56,57]. For example, an altered abundance of Bacteriodetes and Firmicutes has been observed in animals fed a high fat diet [58-60], however as the same diet was to the fed AR and HR birds this could probably explain the lack of differences in bacterial communities between the two groups. Indeed, while the PCoA analysis suggested that there might be distinct bacteria communities along the different segments of the gastrointestinal tract of AR and HR birds (Fig 5), these were not significant (Table 4). 
It is worth noting that we observed a higher relative abundance of Phascolarctobacterium in the ileum of AR birds (Fig 4, c). A higher abundance of Phascolarctobacterium has been correlated with elevated oxidative stress in sows during late gestation and at parturition [61]. Moreover the higher abundance of Phascolarctobacterium has been linked to intestinal inflammation and pathology [62]. Finally, Phascolarctobacterium seems to be correlated with increased body weight and fat mass, and altered metabolic profile [63]. Therefore, in present study, the higher abundance of Phascolarctobacterium observed in the AR birdsmight be linked to the lower production and reproductive performances observed in the AR birds.

It has been reported that the microbiota can also metabolize steroids and produce hormones $[64,65]$. For example, Actinobacteria can regulate the sterols: sterol uptake, eliminate the aliphatic side chain at C17, oxidize the steroid nucleus [66] and synthetize testosterone $[67,68]$. In our study, Actinobacteria abundance in the small intestines was positively correlated with ApoCR (Table 5-1), suggesting that the increased apoptosis cell rate in ovaries could be ascribed to a modification in steroids metabolism induced by the increased abundance of Actinobacteria.

In our study we observed that Spirochaetes (phlum) abundance in the cecum was positively correlated with FCR (Table 5-2). Spirochaetes are responsible for infectious typhlitis in hens[69] which is characterized by decreased egg production and increased the feed consumption[70]. Broiler breeders infected by Spirochaetes had poorer feed conversion and the impact of the disease was also extended to their offspring, with chicks being weak, slow growing and with impaired gastrointestinal functionality[71]. In this study, the lower productive and reproductive performances observed in the AR birds could be partially ascribed to the higher relative abundance of Spirochaetes in the cecum of the AR birds (Table 3-1).

\section{Conclusions}

Overall, our findings suggest that intestinal metabolites: glycerol, inositol play a significant role in fat metabolism though by modulating energy partitioning which can subsequently influence reproductive performances. Also, higher diversity and richness of microbial communities in the small intestines could induce nutrient competition with the host, negatively impacting reproduction. What's more, the higher relative abundance of Phascolarctobacterium (genus), Actinobacteria (phylum) and Spirochaetes (phylum) in the AR birds seems to be correlated to their lower reproduction performances.

\section{Abbreviations}

AR: average reproductive group; HR: high reproductive group; FCR: feed conversion ratio; ApoCR: ovary cell apoptosis rate; HQR: hatchability of qualified egg rate; PCOS: polycystic ovary syndrome; GIT: gastrointestinal; EPR: egg production rate; Duo (D): duodenum; Jej (J): jejunum; lle (I): ileum; Cec (C): cecum; ADFI: average daily feed intake; QR: qualification ratio; PCA: principal component analysis; PLS-DA: partial least squares discriminant analysis; KNN: k-Nearest Neighbor method; VIP: variable importance in the projection; ROC: receiver operating characteristic; AUCs: areas under the curves; KEGG: Kyoto Encyclopedia of Genes and Genomes;

\section{Declarations}

\section{Ethics approval and consent to participate}

This experiment protocol used in the study was approved by the Animal Care and Use Committee of Sichuan Agricultural University.

\section{Consent for publication}

Not applicable.

\section{Availability of data and materials}

The datasets used and/or analyzed during the current study are available from the corresponding author on reasonable request.

\section{Competing interests}

The authors declare that they have no competing interests.

\section{Funding}

This project was financially supported by National Key R\&D Program of China (2017YFD0500500), Broiler Industry Chain Program (2016NZ003-02).

\section{Authors' contributions}

ZY, JW and KZ conceived and designed the experiments; JW, XD and SB performed the experiments; JW and QZ analyzed the data; ZY, wrote the paper; PC, BF, $\mathrm{XM}$, and $\mathrm{XD}$ helped revise this manuscript. All authors read and approved the final manuscript.

\section{Acknowledgements}


The authors would like to thank the help of all staffs in the Poultry Laboratory, Institute of Animal Nutrition, Sichuan Agricultural University.

\section{References}

1.Mazanko MS, Gorlov IF, Prazdnova EV, Makarenko MS, Usatov AV, Bren AB et al. Bacillus probiotic supplementations improve laying performance, egg quality, hatching of laying hens, and sperm quality of roosters. Probiotics Antimicro.2018; 10(2):367-373. https://doi.org/10.1007/s12602-017-9369-4

2.Leeson S. Future considerations in poultry nutrition. Poult Sci.2012; 91(6):1281. https://doi.org/10.3382/ps.2012-02373

3.Bortoluzzi C, Pedroso AA, Mallo JJ, Puyalto M, Kim WK, Applegate TJ. Sodium butyrate improved performance while modulating the cecal microbiota and regulating the expression of intestinal immune-related genes of broiler chickens. Poult Sci.2017; 96(11):3981-3993. https://doi.org/10.3382/ps/pex218

4.Clavijo V, Florez MJV. The gastrointestinal microbiome and its association with the control of pathogens in broiler chicken production: A review. Poult Sci.2018; 97(3):1006-1021. https://doi.org/10.3382/ps/pex359

5.Hadar N, Debelius JW, Rob K, Omry K. Microbial endocrinology: the interplay between the microbiota and the endocrine system. Fems Microbiol Rev.2015; 39(4):509-521. https://doi.org/10.1093/femsre/fuu010

6.Celi P, Cowieson AJ, Fru-Nji F, Steinert RE, Kluenter A-M, Verlhac V. Gastrointestinal functionality in animal nutrition and health: New opportunities for sustainable animal production. Anim Feed Sci Tech.2017:88-100. https://doi.org/10.1016/j.anifeedsci.2017.09.012

7.Funk C, Braune A, Grabber JH, Steinhart H, Bunzel M. Model studies of lignified fiber fermentation by human fecal microbiota and its impact on heterocyclic aromatic amine adsorption. Mutat Res-Fund Mol M.2007; 624(1):41-48. https://doi.org/10.1016/j.mrfmmm.2007.03.010

8.Klaassen CD, Cui JY. Review: Mechanisms of how the intestinal microbiota alters the effects of drugs and bile acids. Drug Metab Dispos.2015; 43(10):1505-1521. https://doi.org/10.1124/dmd.115.065698

9.Prayoonthien P, Nitisinprasert S, Keawsompong S. In vitro fermentation of copra meal hydrolysate by chicken microbiota. 3 Biotech.2018; 8(1):41. https://doi.org/10.1007/s13205-017-1058-1

10.Trompette A, Gollwitzer ES, Yadava K, Sichelstiel AK, Sprenger N, Ngom-Bru C et al. Gut microbiota metabolism of dietary fiber influences allergic airway disease and hematopoiesis. Nat Med.2014; 20(2):159-166. https://doi.org/10.1038/nm.3444

11.Lee K, Lillehoj HS, Siragusa GR. Direct-fed microbials and their impact on the intestinal microflora and immune system of chickens. J Poult Sci.2010:1001160039. https://doi.org/10.2141/jpsa.009096

12.Hooper LV, Littman DR, Macpherson AJ. Interactions between the microbiota and the immune system. Science.2012; 336(6086):1268-1273. https://doi.org/10.1126/science. 1223490

13.Clark A, Mach N. Exercise-induced stress behavior, gut-microbiota-brain axis and diet: a systematic review for athletes. J Int Soc Sports Nutr.2016; 13:43. https://doi.org/10.1186/s12970-016-0155-6

14.Backhed F, Ding H, Wang T, Hooper LV, Koh GY, Nagy A et al. The gut microbiota as an environmental factor that regulates fat storage. P Natl Acad Sci USA.2004; 101(44):15718-15723. https://doi.org/10.1073/pnas.0407076101

15.Wen C, Yan W, Sun C, Ji C, Zhou Q, Zhang D et al. The gut microbiota is largely independent of host genetics in regulating fat deposition in chickens. Isme J.2019; 13(6):1422-1436. https://doi.org/10.1038/s41396-019-0367-2

16.Sonnenburg JL, Backhed F. Diet-microbiota interactions as moderators of human metabolism. Nature.2016; 535(7610):56-64. https://doi.org/10.1038/nature18846

17.Nahashon SN, Nakaue HS, Snyder SP, Mirosh LW. Performance of single comb White Leghorn layers fed corn-soybean meal and barley-corn-soybean meal diets supplemented with a direct-fed microbial. Poult Sci.1994; 73(11):1712-1723. https://doi.org/10.3382/ps.0731712

18.Karl JP, Meydani M, Barnett JB, Vanegas SM, Barger K, Fu X et al. Fecal concentrations of bacterially derived vitamin $\mathrm{K}$ forms are associated with gut microbiota composition but not plasma or fecal cytokine concentrations in healthy adults. Am J Clin Nutr.2017; 106(4):1052-1061.

https://doi.org/10.3945/ajcn.117.155424

19.Magnusdottir S, Ravcheev D, de Crecy-Lagard V, Thiele I. Systematic genome assessment of B-vitamin biosynthesis suggests co-operation among gut microbes. Front Genet.2015; 6:148. https://doi.org/10.3389/fgene.2015.00148

20.Presti I, D’Orazio G, Labra M, La Ferla B, Mezzasalma V, Bizzaro G et al. Evaluation of the probiotic properties of new Lactobacillus and Bifidobacterium strains and their in vitro effect. Appl Microbiol Biotechnol.2015; 99(13):5613-5626. https://doi.org/10.1007/s00253-015-6482-8

21.Celi P, Verlhac V, Calvo EP, Schmeisser J, Kluenter A-M. Biomarkers of gastrointestinal functionality in animal nutrition and health. Anim Feed Sci Tech.2019; 250:9-31. https://doi.org/10.1016/j.anifeedsci.2018.07.012 
22.Tremellen K, Pearce K. Dysbiosis of gut microbiota (DOGMA) - A novel theory for the development of polycystic ovarian syndrome. Med Hypotheses.2012; 79(1):104-112. https://doi.org/10.1016/j.mehy.2012.04.016

23.Escobar-Morreale HF, Millán JL, San. Abdominal adiposity and the polycystic ovary syndrome. Trends Endocrin Met.2007; 18(7):266-272. https://doi.org/10.1016/j.tem.2007.07.003

24.Gavrieli Y, Sherman Y, Ben-Sasson SA. Identification of programmed cell death in situ via specific labeling of nuclear DNA fragmentation. Journal Cell Biol.1992; 119(3):493-501. https://doi.org/10.1083/jcb.119.3.493

25.Magoc T, Salzberg SL. FLASH: fast length adjustment of short reads to improve genome assemblies. Bioinformatics.2011; 27(21):2957-2963. https://doi.org/10.1093/bioinformatics/btr507

26.Caporaso JG, Kuczynski J, Stombaugh J, Bittinger K, Bushman FD, Costello EK et al. QIIME allows analysis of high-throughput community sequencing data. Nat Methods.2010; 7(5):335-336. https://doi.org/10.1038/nmeth.f.303

27.Edgar RC, Haas BJ, Clemente JC, Quince C, Knight R. UCHIME improves sensitivity and speed of chimera detection. Bioinformatics.2011; 27(16):21942200. https://doi.org/10.1093/bioinformatics/btr381

28.Edgar RC. UPARSE: highly accurate OTU sequences from microbial amplicon reads. Nat Methods.2013; 10(10):996-998. https://doi.org/10.1038/nmeth.2604

29.DeSantis TZ, Hugenholtz P, Larsen N, Rojas M, Brodie EL, Keller K et al. Greengenes, a chimera-checked 16S rRNA gene database and workbench compatible with ARB. Appl Environ Microbiol.2006; 72(7):5069-5072. https://doi.org/10.1128/aem.03006-05

30.Wang Q, Garrity GM, Tiedje JM, Cole JR. Naive Bayesian classifier for rapid assignment of rRNA sequences into the new bacterial taxonomy. Appl Environ Microbiol.2007; 73(16):5261-5267. https://doi.org/10.1128/aem.00062-07

31.Algina J, Keselman HJ. Comparing squared multiple correlation coefficients: Examination of a confidence interval and a test significance. Psychol Methods.1999; 4(1):76-83. https://doi.org/10.1037/1082-989X.4.1.76

32.Smith CA, Want EJ, O'Maille G, Abagyan R, Siuzdak G. XCMS: processing mass spectrometry data for metabolite profiling using nonlinear peak alignment, matching, and identification. Analytical chemistry.2006; 78(3):779-787. https://doi.org/10.1021/ac051437y

33.Oberacher H, Whitley G, Berger B. Evaluation of the sensitivity of the 'Wiley registry of tandem mass spectral data, MSforlD' with MS/MS data of the 'NIST/NIH/EPA mass spectral library'. J Mass Spectrom.2013; 48(4):487-496. https://doi.org/10.1002/jms.3184

34.Hastie T, Tibshirani R, Narasimhan B, Chu G: Impute: Imputation for Microarray Data. R package version 1.44.40. In.; 2014.

35.Chan EC, Pasikanti KK, Nicholson JK. Global urinary metabolic profiling procedures using gas chromatography-mass spectrometry. Nat protoc.2011; 6(10):1483-1499. https://doi.org/10.1038/nprot.2011.375

36.Dunn WB, Broadhurst D, Begley P, Zelena E, Francis-Mclntyre S, Anderson N et al. Procedures for large-scale metabolic profiling of serum and plasma using gas chromatography and liquid chromatography coupled to mass spectrometry. Nat protoc.2011; 6(7):1060-1083. https://doi.org/10.1038/nprot.2011.335

37.Xia X, Li G, Ding Y, Ren T, Zheng J, Kan J. Effect of whole grain Qingke (Tibetan Hordeum vulgare L. Zangqing 320) on the serum lipid levels and intestinal microbiota of rats under high-fat diet. J Agric Food Chem.2017; 65(13):2686-2693. https://doi.org/10.1021/acs.jafc.6b05641

38.Scott KPD, S. H, Flint HJ. Dietary fibre and the gut microbiota. Food Nutr Bull.2010; 33(3):201-211. https://doi.org/10.1111/j.1467-3010.2008.00706.x

39.Apajalahti J, Vienola K. Interaction between chicken intestinal microbiota and protein digestion. Anim Feed Sci Tech.2016; 221:323-330.

https://doi.org/10.1016/j.anifeedsci.2016.05.004

40.Wang J, Yue H, Wu S, Zhang H, Qi G. Nutritional modulation of health, egg quality and environmental pollution of the layers. Anim Nutr.2017; 3(2):91-96. https://doi.org/10.1016/j.aninu.2017.03.001

41.Johnson AL, Woods DC. Dynamics of avian ovarian follicle development: cellular mechanisms of granulosa cell differentiation. Gen Comp Endocrinol.2009; 163(1-2):12-17. https://doi.org/10.1016/j.ygcen.2008.11.012

42.Richards MP, Poch SM, Coon CN, Rosebrough RW, Ashwell CM, McMurtry JP. Feed restriction significantly alters lipogenic gene expression in broiler breeder chickens. J Nutr.2003; 133(3):707-715. https://doi.org/10.1093/jn/133.3.707

43.Richards MP, Proszkowiec-Weglarz M. Mechanisms regulating feed intake, energy expenditure, and body weight in poultry. Poult Sci.2007; 86(7):14781490. https://doi.org/10.1093/ps/86.7.1478

44.Chen SE, McMurtry JP, Walzem RL. Overfeeding-induced ovarian dysfunction in broiler breeder hens is associated with lipotoxicity. Poult Sci.2006; 85(1):70-81. https://doi.org/10.1093/ps/85.1.70 
45.Walzem RL, Davis PA, Hansen RJ. Overfeeding increases very low density lipoprotein diameter and causes the appearance of a unique lipoprotein particle in association with failed yolk deposition. J Lipid Res.1994; 35(8):1354-1366.

46.Pan YE, Liu ZC, Chang CJ, Xie YL, Chen CY, Chen CF et al. Ceramide accumulation and up-regulation of proinflammatory interleukin-1beta exemplify lipotoxicity to mediate declines of reproductive efficacy of broiler hens. Domest Anim Endocrinol.2012; 42(3):183-194.

https://doi.org/10.1016/j.domaniend.2011.12.001

47.Bilgili SF, Renden JA. Relationship of body fat to fertility in broiler breeder hens. Poult Sci.1985; 64(7):1394-1396. https://doi.org/10.3382/ps.0641394

48.Xie YL, Pan YE, Chang CJ, Tang PC, Huang YF, Walzem RL et al. Palmitic acid in chicken granulosa cell death-lipotoxic mechanisms mediate reproductive inefficacy of broiler breeder hens. Theriogenology.2012; 78(9):1917-1928. https://doi.org/10.1016/j.theriogenology.2012.07.004

49.Witty JP, Bridgham JT, Johnson AL. Induction of apoptotic cell death in hen granulosa cells by ceramide. Endocrinology.1996; 137(12):5269-5277. https://doi.org/10.1210/endo.137.12.8940345

50.Listenberger LL, Ory DS, Schaffer JE. Palmitate-induced apoptosis can occur through a ceramide-independent pathway. J Biol Chem.2001; 276(18):1489014895. https://doi.org/10.1074/jbc.M010286200

51.Mu YM, Yanase T, Nishi Y, Tanaka A, Saito M, Jin CH et al. Saturated FFAs, palmitic acid and stearic acid, induce apoptosis in human granulosa cells. Endocrinology.2001; 142(8):3590-3597. https://doi.org/10.1210/endo.142.8.8293

52.Zhou J, Chen J, Hu C, Xie Z, Li H, Wei S et al. Exploration of the serum metabolite signature in patients with rheumatoid arthritis using gas chromatographymass spectrometry. J Pharm Biomed Anal.2016; 127:60-67. https://doi.org/10.1016/j.jpba.2016.02.004

53.Sun LW, Zhang HY, Wu L, Shu S, Xia C, Xu C et al. (1)H-Nuclear magnetic resonance-based plasma metabolic profiling of dairy cows with clinical and subclinical ketosis. J Dairy Sci.2014; 97(3):1552-1562. https://doi.org/10.3168/jds.2013-6757

54.Videnska P, Faldynova M, Juricova H, Babak V, Sisak F, Havlickova H et al. Chicken faecal microbiota and disturbances induced by single or repeated therapy with tetracycline and streptomycin. BMC Vet Res.2013; 9(1):30. https://doi.org/10.1186/1746-6148-9-30

55.Xiao Y, Xiang Y, Zhou W, Chen J, Li K, Yang H. Microbial community mapping in intestinal tract of broiler chicken. Poult Sci.2017; 96(5):1387-1393. https://doi.org/10.3382/ps/pew372

56.Power SE, O’Toole PW, Stanton C, Ross RP, Fitzgerald GF. Intestinal microbiota, diet and health. Br J Nutr.2014; 111(3):387-402. https://doi.org/10.1017/S0007114513002560

57.Morgan NK, Walk CL, Bedford MR, Burton EJ. The effect of dietary calcium inclusion on broiler gastrointestinal pH: quantification and method optimization. Poult Sci.2014; 93(2):354-363. https://doi.org/10.3382/ps.2013-03305

58.Ley RE, Fredrik BC, Peter T, Lozupone CA, Knight RD, Gordon JI. Obesity alters gut microbial ecology. P Natl Acad Sci USA.2005. https://doi.org/10.1073/pnas.0504978102

59.Mujico JR, Baccan GC, Gheorghe A, Diaz LE, Marcos A. Changes in gut microbiota due to supplemented fatty acids in diet-induced obese mice. Br J Nutr.2013; 110(4):711-720. https://doi.org/10.1017/s0007114512005612

60.Serino M, Luche E, Gres S, Baylac A, Berge M, Cenac C et al. Metabolic adaptation to a high-fat diet is associated with a change in the gut microbiota. Gut.2012; 61(4):543-553. https://doi.org/10.1136/gutjnl-2011-301012

61.Wang H, Ji Y, Yin C, Deng M, Tang T, Deng B et al. Differential analysis of gut microbiota correlated with oxidative stress in sows with high or low litter performance during lactation. Front Microbiol.2018; 9:1665. https://doi.org/10.3389/fmicb.2018.01665

62.Dicksved J, Ellstrom P, Engstrand L, Rautelin H. Susceptibility to Campylobacter infection is associated with the species composition of the human fecal microbiota. M Bio.2014; 5(5):e01212-01214. https://doi.org/10.1128/mBio.01212-14

63.Lecomte V, Kaakoush NO, Maloney CA, Raipuria M, Huinao KD, Mitchell HM et al. Changes in gut microbiota in rats fed a high fat diet correlate with obesityassociated metabolic parameters. PLoS One.2015; 10(5):e0126931. https://doi.org/10.1371/journal.pone.0126931

64.Miller MB, Bassler BL. Quorum sensing in bacteria. Annu Rev Microbiol.2001; 55:165-199. https://doi.org/10.1146/annurev.micro.55.1.165

65.Waters CM, Bassler BL. Quorum sensing: cell-to-cell communication in bacteria. Annu Rev Cell Dev Biol.2005; 21:319-346.

https://doi.org/10.1146/annurev.cellbio.21.012704.131001

66.Donova MV, Egorova OV. Microbial steroid transformations: current state and prospects. Appl Microbiol Biotechnol.2012; 94(6):1423-1447. https://doi.org/10.1007/s00253-012-4078-0

67.Liu WH, Kuo CW, Wu KL, Lee CY, Hsu WY. Transformation of cholesterol to testosterone by Mycobacterium sp. J Ind Microbiol Biot.1994; 13(3):167-171. https://doi.org/10.1007/BF01584002 
68.Egorova OV, Nikolayeva VM, Sukhodolskaya GV, Donova MV. Transformation of C19-steroids and testosterone production by sterol-transforming strains of Mycobacterium spp. J Mol Catal B-Enzym.2009; 57(1):198-203. https://doi.org/10.1016/j.molcatb.2008.09.003

69.Davelaar FG, Smit HF, Hovind-Hougen K, Dwars RM, Vandervalk PC. Infectious typhlitis in chickens caused by spirochetes. Avian pathol.1986; 15(2):247258. https://doi.org/10.1080/03079458608436285

70.Dwars RM, Davelaar FG, Smit HF. Infection of broiler parent hens with avian intestinal spirochaetes: Effects on egg production and chick quality. Avian pathol.1993; 22(4):693-701. https://doi.org/10.1080/03079459308418957

71.Smit HF, Dwars RM, Davelaar FG, Wijtten GA. Observations on the influence of intestinal spirochaetosis in broiler breeders on the performance of their progeny and on egg production. Avian pathol.1998; 27(2):133-141. https://doi.org/10.1080/03079459808419314

\section{Tables}

Table 1. Difference in productive performance between AR and HR broiler breeders $(n=10)^{1}$

\begin{tabular}{|c|c|c|c|c|c|c|c|}
\hline \multirow[t]{2}{*}{ Item } & \multirow[t]{2}{*}{ EPR (\%) } & \multirow[t]{2}{*}{ Egg weight (\%) } & \multirow[t]{2}{*}{ ADFI } & \multirow[t]{2}{*}{ FCR } & \multirow[t]{2}{*}{ QR (\%) } & \multicolumn{2}{|c|}{ HQR (\%) } \\
\hline & & & & & & $3 W k$ & $6 \mathrm{Wk}$ \\
\hline$\overline{A R}$ & 77.26 & 66.39 & 161.83 & 3.16 & 90.86 & 92.92 & 84.17 \\
\hline HR & 86.67 & 64.15 & 161.83 & 2.92 & 93.80 & 91.64 & 98.33 \\
\hline SEM & 0.008 & 0.805 & - & 0.042 & 0.029 & 0.033 & 0.411 \\
\hline P-Value & $<0.01$ & 0.07 & - & $<0.01$ & 0.20 & 0.79 & 0.04 \\
\hline
\end{tabular}

${ }^{1}$ Each mean represents 10 cages, with one layer/cage. Abbreviations represented: EPR = egg production rate; $A D F I=$ average daily feed intake; $F C R=$ feed conversion ratio; $\mathrm{QR}$ = qualification ratio; $\mathrm{HQR}$ = hatchability of qualified egg rate.

Table 2. Difference in relative gastrointestinal organ weight between AR and HR broiler breeders $(n=10)$

\begin{tabular}{|c|c|c|c|c|c|c|c|c|c|}
\hline Item & Live weight, $\mathrm{kg}$ & Crop (\%) & Proventriculus (\%) & Abdominal fat (\%) & Gizzard (\%) & Duodenum (\%) & Jejunum (\%) & Ileum (\%) & Cecum (\%) \\
\hline$\overline{A R}$ & 4.08 & 0.35 & 0.21 & 2.99 & 0.84 & 0.29 & 0.45 & 0.39 & 0.23 \\
\hline HR & 4.15 & 0.40 & 0.20 & 2.36 & 0.88 & 0.27 & 0.46 & 0.36 & 0.22 \\
\hline SEM & 0.089 & $<0.01$ & $<0.01$ & 0.21 & $<0.01$ & $<0.01$ & $<0.01$ & $<0.01$ & $<0.01$ \\
\hline P-value & 0.59 & 0.11 & 0.80 & $<0.05$ & 0.26 & 0.57 & 0.82 & 0.45 & 0.88 \\
\hline
\end{tabular}

Table 3-1. Differences in the relative abundance of dominant microbiota (phylum) ratio in different intestinal segments of AR and HR broiler breeders

\begin{tabular}{|c|c|c|c|c|c|c|c|c|c|c|c|}
\hline Phylum & Group & Firmicutes & Bacteroidetes & Fusobacteria & Proteobacteria & Cyanobacteria & Spirochaetes & Verrucomicrobia & Tenericutes & Euryarchaeota & Deferribact \\
\hline \multirow[t]{2}{*}{ Duodenum } & AR & $70.97 \%$ & $0.85 \%$ & $0.09 \%$ & $19.73 \%$ & $7.96 \%$ & $0.02 \%$ & $0.01 \%$ & $0.03 \%$ & $0.01 \%$ & $0.00 \%$ \\
\hline & $H R$ & $73.92 \%$ & $0.57 \%$ & $0.08 \%$ & $14.78 \%$ & $10.28 \%$ & $0.01 \%$ & $0.01 \%$ & $0.03 \%$ & $0.00 \%$ & $0.00 \%$ \\
\hline \multirow[t]{2}{*}{ Jejunum } & AR & $71.12 \%$ & $0.48 \%$ & $0.05 \%$ & $6.08 \%$ & $21.73 \%$ & $0.01 \%$ & $0.01 \%$ & $0.03 \%$ & $0.01 \%$ & $0.00 \%$ \\
\hline & $H R$ & $73.30 \%$ & $0.38 \%$ & $0.04 \%$ & $9.42 \%$ & $16.34 \%$ & $0.01 \%$ & $0.01 \%$ & $0.01 \%$ & $0.00 \%$ & $0.00 \%$ \\
\hline \multirow[t]{2}{*}{ Ileum } & AR & $75.58 \%$ & $6.12 \%$ & $0.15 \%$ & $5.88 \%$ & $11.73 \%$ & $0.14 \%$ & $0.01 \%$ & $0.03 \%$ & $0.02 \%$ & $0.01 \%$ \\
\hline & $\mathrm{HR}$ & $72.28 \%$ & $3.24 \%$ & $0.57 \%$ & $5.43 \%$ & $16.07 \%$ & $1.72 \%$ & $0.06 \%$ & $0.09 \%$ & $0.01 \%$ & $0.12 \%$ \\
\hline \multirow[t]{2}{*}{ Cecum } & $A R$ & $38.79 \%$ & $48.44 \%$ & $2.90 \%$ & $4.02 \%$ & $0.61 \%$ & $1.21 \%$ & $0.74 \%$ & $0.74 \%$ & $1.04 \%$ & $0.62 \%$ \\
\hline & $\mathrm{HR}$ & $41.76 \%$ & $45.09 \%$ & $2.15 \%$ & $4.85 \%$ & $0.68 \%$ & $0.99 \%$ & $1.42 \%$ & $0.55 \%$ & $1.01 \%$ & $0.67 \%$ \\
\hline
\end{tabular}


Table 3-2. Differences in the relative abundance of dominant microbiota (genus) ratio in different intestinal segments of AR and HR broiler breeders

\begin{tabular}{|c|c|c|c|c|c|c|c|c|c|c|}
\hline Genus & Group & Lactobacillus & Fusobacterium & unidentified_Chloroplast & Helicobacter & Bacteroides & Phyllobacterium & Lactococcus & Brachyspira & Rikenellaceae_RCC \\
\hline \multirow[t]{2}{*}{ Duodenum } & AR & $64.92 \%$ & $0.09 \%$ & $7.95 \%$ & $9.38 \%$ & $0.49 \%$ & $9.15 \%$ & $0.00 \%$ & $0.00 \%$ & $0.07 \%$ \\
\hline & $\mathrm{HR}$ & $70.22 \%$ & $0.08 \%$ & $10.28 \%$ & $7.95 \%$ & $0.33 \%$ & $5.08 \%$ & $0.00 \%$ & $0.00 \%$ & $0.04 \%$ \\
\hline \multirow[t]{2}{*}{ Jejunum } & AR & $63.37 \%$ & $0.05 \%$ & $21.72 \%$ & $1.37 \%$ & $0.27 \%$ & $1.61 \%$ & $0.00 \%$ & $0.01 \%$ & $0.03 \%$ \\
\hline & HR & $69.22 \%$ & $0.04 \%$ & $16.34 \%$ & $5.16 \%$ & $0.23 \%$ & $1.70 \%$ & $0.00 \%$ & $0.00 \%$ & $0.02 \%$ \\
\hline \multirow[t]{2}{*}{ Ileum } & AR & $61.54 \%$ & $0.15 \%$ & $11.72 \%$ & $1.05 \%$ & $3.83 \%$ & $2.60 \%$ & $0.00 \%$ & $0.09 \%$ & $0.53 \%$ \\
\hline & HR & $56.54 \%$ & $0.57 \%$ & $16.05 \%$ & $0.97 \%$ & $2.19 \%$ & $0.65 \%$ & $0.00 \%$ & $1.60 \%$ & $0.21 \%$ \\
\hline \multirow[t]{2}{*}{ Cecum } & AR & $0.41 \%$ & $2.90 \%$ & $0.03 \%$ & $0.06 \%$ & $25.65 \%$ & $0.03 \%$ & $0.00 \%$ & $0.09 \%$ & $5.63 \%$ \\
\hline & HR & $5.00 \%$ & $2.15 \%$ & $0.20 \%$ & $0.25 \%$ & $23.64 \%$ & $0.43 \%$ & $0.00 \%$ & $0.05 \%$ & $3.83 \%$ \\
\hline
\end{tabular}

Table 4. Adonis analysis of differences between groups

\begin{tabular}{lllllll}
\hline Vs_group & Df & SumsOfSqs & MeanSqs & F.Model & $\mathrm{R}^{2}$ & $\operatorname{Pr}(>\mathrm{F})$ \\
\hline HR.D-AR.D & $1(14)$ & $0.02(0.75)$ & $0.02(0.05)$ & 0.40 & $0.03(0.97)$ & 0.84 \\
\hline HR.J-AR.J & $1(14)$ & $0.05(0.89)$ & $0.05(0.06)$ & 0.78 & $0.05(0.95)$ & 0.47 \\
\hline HR.I-AR.I & $1(14)$ & $0.08(1.50)$ & $0.08(0.11)$ & 0.70 & $0.05(0.95)$ & 0.68 \\
\hline HR.C-AR.C & $1(14)$ & $0.07(1.06)$ & $0.07(0.08)$ & 0.87 & $0.06(0.94)$ & 0.65 \\
\hline HR.VA-AR.VA & $1(10)$ & $0.20(1.03)$ & $0.20(0.10)$ & 1.89 & $0.16(0.84)$ & 0.07 \\
\hline HR.CL-AR.CL & $1(10)$ & $0.14(0.77)$ & $0.14(0.08)$ & 1.76 & $0.15(0.85)$ & 0.14 \\
\hline
\end{tabular}

Table 5-1. Correlation between dominant bacteria in the small intestine with broiler breeders' reproductive performance

\begin{tabular}{|c|c|c|c|c|c|}
\hline & \multirow[t]{2}{*}{ Microbiota } & \multicolumn{3}{|c|}{ Reproductive performance } & \multirow{2}{*}{$\begin{array}{l}\text { Ovary apoptosis } \\
\text { ApoCR }\end{array}$} \\
\hline & & EPR & FCR & HQR & \\
\hline \multirow[t]{10}{*}{ Phylum } & Firmicutes & 0.11 & -0.19 & 0.02 & -0.10 \\
\hline & Proteobacteria & -0.08 & 0.11 & 0.01 & -0.04 \\
\hline & Cyanobacteria & -0.10 & 0.09 & 0.14 & 0.10 \\
\hline & Bacteroidetes & -0.24 & 0.24 & -0.19 & 0.23 \\
\hline & Spirochaetes & -0.27 & 0.24 & -0.15 & 0.20 \\
\hline & Fusobacteria & -0.22 & 0.23 & -0.23 & 0.23 \\
\hline & Actinobacteria & -0.11 & 0.23 & 0.13 & $0.34^{*}$ \\
\hline & Deferribacteres & -0.16 & 0.11 & -0.10 & 0.27 \\
\hline & Euryarchaeota & $-0.54^{\star}$ & $0.54^{\star}$ & $-0.37 *$ & $0.52^{\star}$ \\
\hline & Synergistetes & $-0.36^{\star}$ & $0.32^{\star}$ & -0.22 & 0.16 \\
\hline \multirow[t]{10}{*}{ Genus } & Lactobacillus & 0.13 & -0.21 & 0.09 & -0.07 \\
\hline & unidentified_Chloroplast & -0.10 & 0.09 & 0.14 & 0.10 \\
\hline & Helicobacter & 0.16 & -0.12 & 0.02 & -0.11 \\
\hline & Phyllobacterium & $-0.29 \star$ & $0.30 *$ & -0.21 & 0.08 \\
\hline & Bacteroides & -0.24 & 0.21 & -0.20 & 0.23 \\
\hline & Brachyspira & -0.12 & 0.10 & -0.06 & 0.10 \\
\hline & Romboutsia & $-0.29 \star$ & 0.22 & -0.14 & 0.14 \\
\hline & Megamonas & $-0.40^{\star}$ & 0.26 & -0.24 & 0.25 \\
\hline & Gallibacterium & -0.05 & 0.02 & 0.14 & 0.17 \\
\hline & Coprococcus_1 & $-0.31^{\star}$ & 0.27 & -0.28 & 0.17 \\
\hline
\end{tabular}


Table 5-2. The correlation between dominant bacteria in the cecum with broiler breeders' reproductive performance

\begin{tabular}{|c|c|c|c|c|c|}
\hline & \multirow[t]{2}{*}{ Microbiota } & \multicolumn{3}{|c|}{ Reproductive performance } & \multirow{2}{*}{$\begin{array}{l}\text { Ovary apoptosis } \\
\text { ApoCR }\end{array}$} \\
\hline & & EPR & FCR & HQR & \\
\hline \multirow[t]{10}{*}{ Phylum } & Bacteroidetes & -0.34 & 0.29 & -0.15 & 0.23 \\
\hline & Firmicutes & 0.35 & -0.42 & 0.05 & -0.24 \\
\hline & Fusobacteria & -0.15 & -0.05 & 0.14 & 0.16 \\
\hline & Proteobacteria & 0.06 & -0.01 & 0.29 & -0.02 \\
\hline & Verrucomicrobia & -0.09 & 0.18 & -0.07 & 0.09 \\
\hline & Spirochaetes & -0.43 & $0.54^{\star}$ & -0.08 & 0.46 \\
\hline & Euryarchaeota & 0.03 & -0.05 & -0.02 & 0.03 \\
\hline & Tenericutes & -0.01 & -0.09 & -0.18 & -0.22 \\
\hline & Cyanobacteria & 0.13 & -0.04 & -0.10 & -0.01 \\
\hline & Planctomycetes & -0.25 & 0.31 & $-0.62^{*}$ & 0.42 \\
\hline \multirow[t]{10}{*}{ Genus } & Bacteroides & -0.32 & 0.00 & -0.34 & 0.20 \\
\hline & Lactobacillus & 0.48 & -0.43 & 0.04 & -0.33 \\
\hline & Fusobacterium & -0.15 & -0.05 & 0.14 & 0.16 \\
\hline & Methanobrevibacter & 0.16 & -0.21 & 0.01 & 0.02 \\
\hline & Alloprevotella & -0.08 & 0.00 & -0.48 & 0.01 \\
\hline & Tyzzerella & 0.07 & -0.02 & 0.04 & -0.08 \\
\hline & Ruminococcaceae_NK4A214_group & -0.44 & 0.38 & -0.17 & 0.07 \\
\hline & Helicobacter & 0.32 & -0.14 & 0.02 & -0.18 \\
\hline & Sphaerochaeta & $-0.70 *$ & 0.48 & -0.35 & 0.47 \\
\hline & Parabacteroides & -0.45 & 0.30 & -0.21 & 0.32 \\
\hline
\end{tabular}

Table 6. Different metabolites measured in the ileum and cecum of AR and HR broiler breeders.

\begin{tabular}{|c|c|c|c|c|c|}
\hline Items $^{1}$ & Name_des & $\mathrm{FC}$ & $\log _{2} F C$ & P-value & Change \\
\hline \multirow[t]{5}{*}{ Ileum } & Octadecanoic acid & 6.47 & 2.70 & $<0.05$ & up \\
\hline & d-Ribose & 11.08 & 3.47 & $<0.05$ & up \\
\hline & Inositol & 13.60 & 3.77 & $<0.05$ & up \\
\hline & 9,12-Octadecadienoic acid & 13.69 & 3.78 & $<0.05$ & up \\
\hline & 11-trans-Octadecenoic acid & 7.48 & 2.90 & $<0.05$ & up \\
\hline Cecum & Inositol & 0.41 & -1.30 & $<0.05$ & down \\
\hline
\end{tabular}

${ }^{1}$ Abbreviation indicate: $\mathrm{FC}=$ fold change.

\section{Figures}
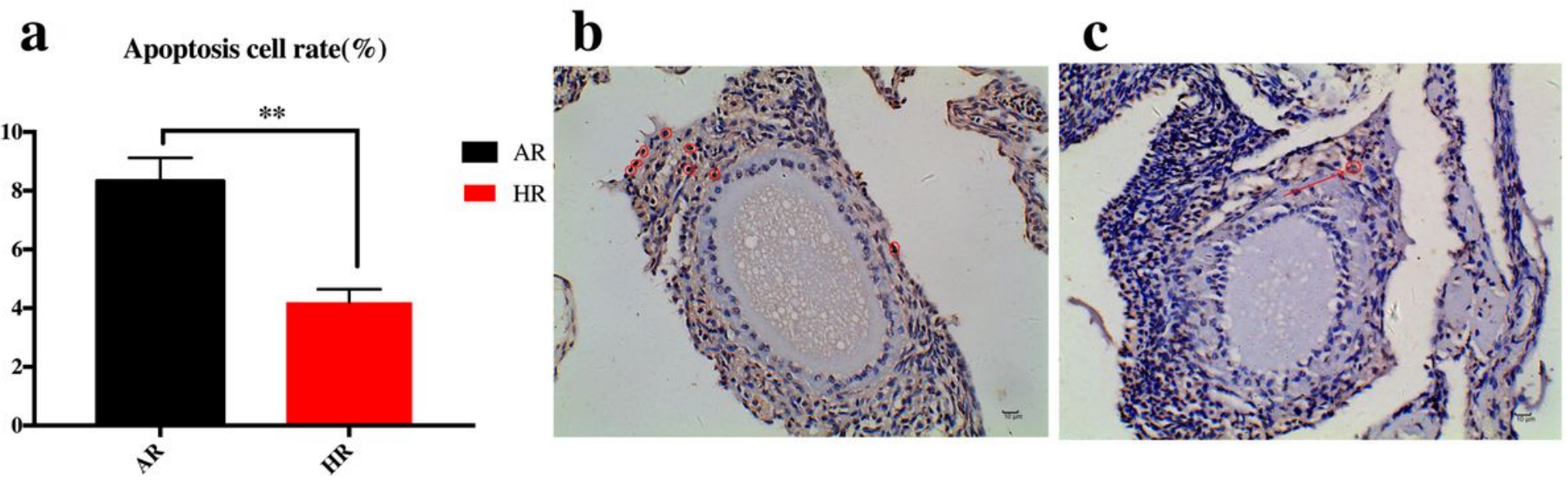

Figure 1

Differences in ovary apoptosis rate (a) between AR and HR broiler breeders. Ovary of AR (b) and HR (c) birds; apoptotic cells are marked with red circle. 

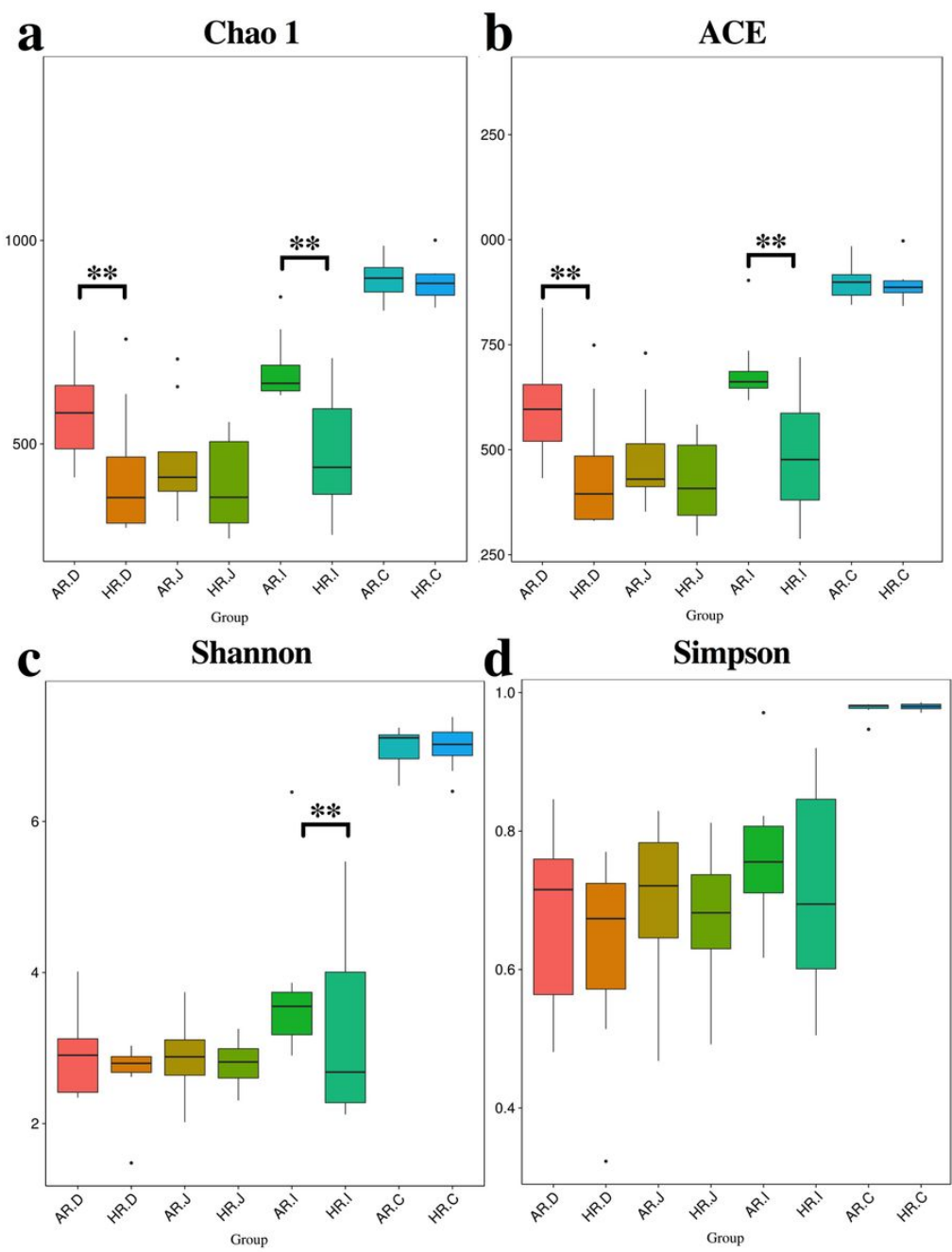

\section{Figure 2}

Differences in richness $(a, b)$, diversity (c, d) index in the duodenum (AR.D), jejunum (AR.J), ileum (AR.I), cecum (AR.C) of AR and the duodenum (HR.D) , jejunum (HR.J), ileum (HR.I), cecum (HR.C) of HR.
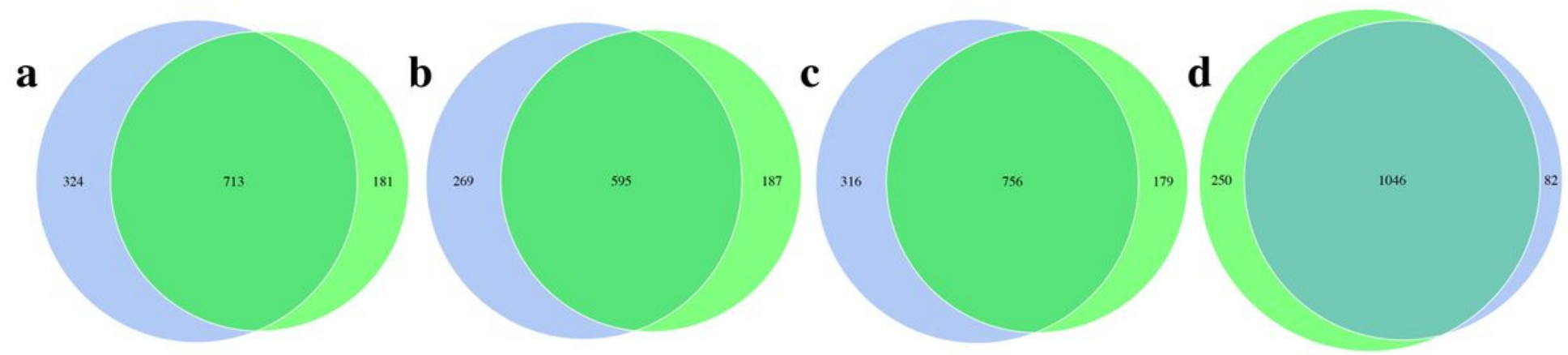

Figure 3

Differences in OTUs distribution. The Venn diagrams are used to describe common and unique OTUs between goups. duodenum AR-HR (a), jejunum AR-HR (b), ileum AR-HR (c), cecum AR-HR (d). 
$\mathbf{a}$

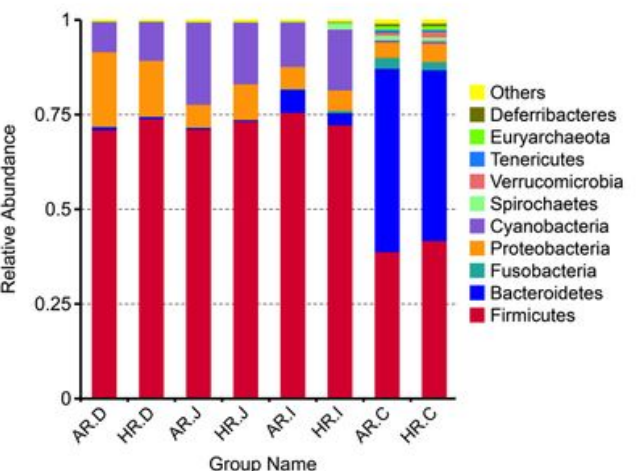

C

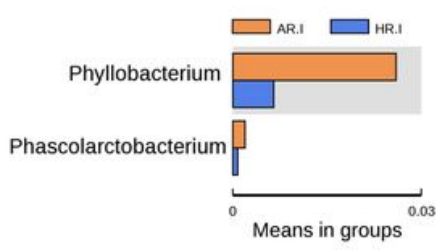

b
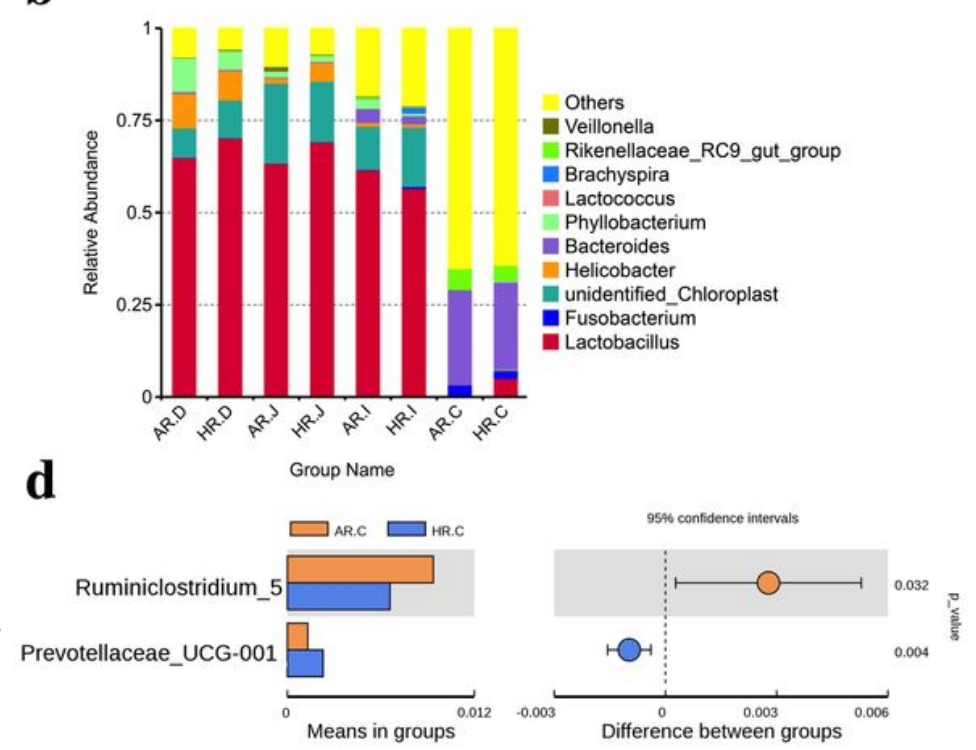

Figure 4

Differnces in relative abundance levels of the bacterial phyla (a) and genera (b) in the duodenum (AR.D), jejunum (AR.J), ileum (AR.I), cecum (AR.C) of AR and the duodenum (HR.D) , jejunum (HR.J), ileum (HR.I), cecum (HR.C) of HR. T-test based on the relative abundance levels of the bacterial. T-test on ileal bacteria (c), caecal bacteria (d) at genus level.

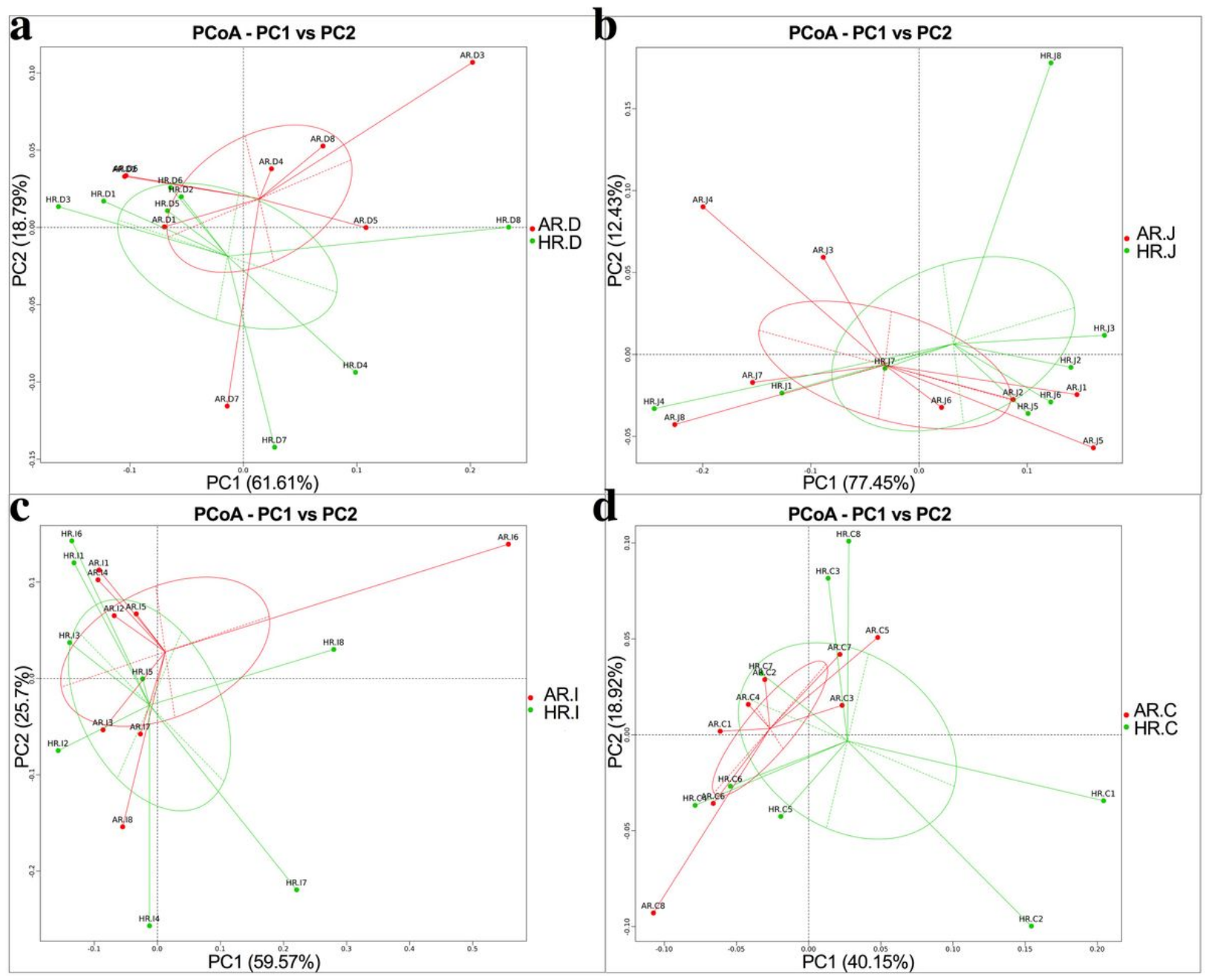


Figure 5

Principal coordinate analysis (PCoA) of microbial comunities in the duodenum (a), jejunum (b), ileum (c), cecum (d), of AR and HR broiler breeders.

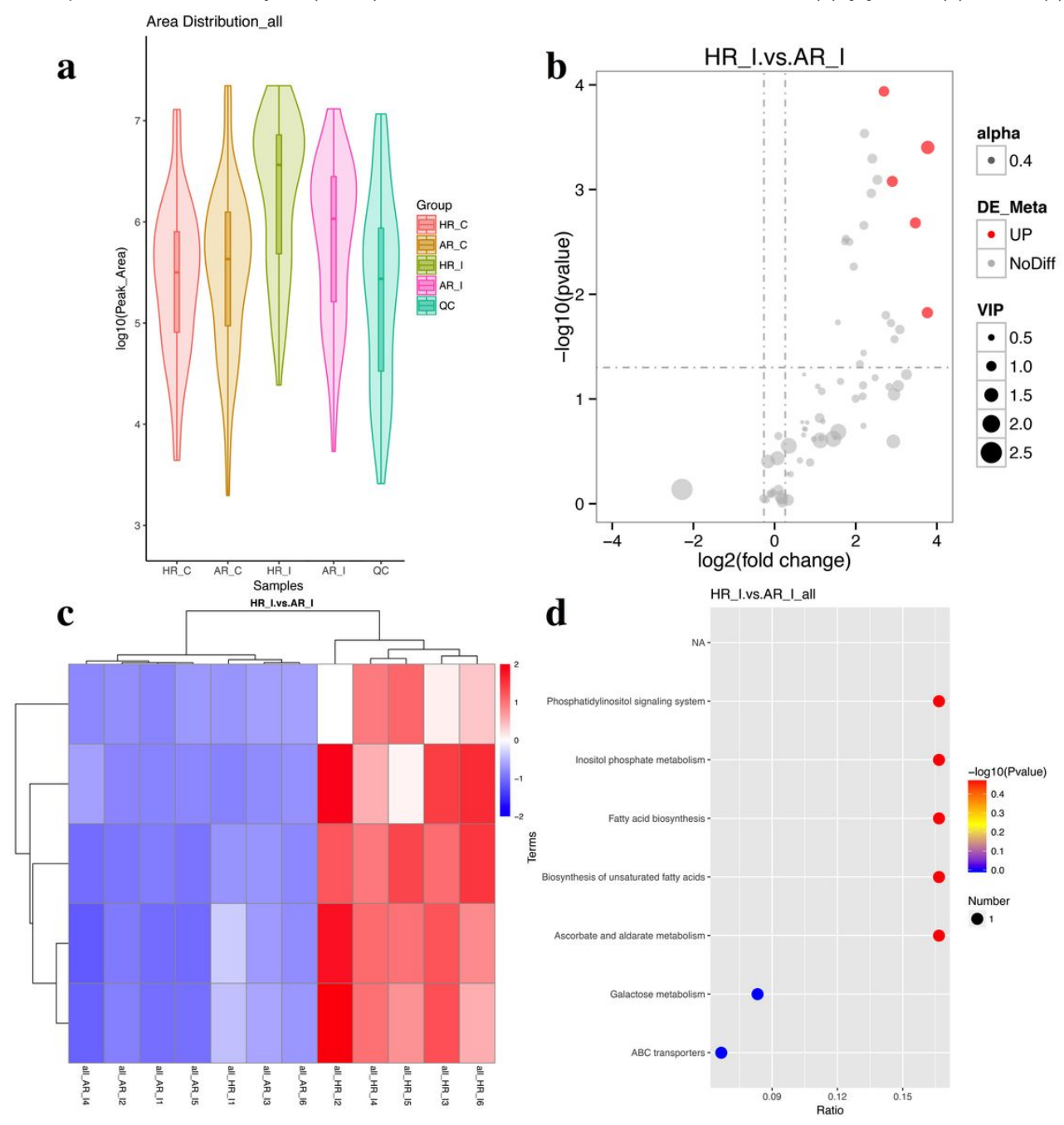

Figure 6

a: Expression and distribution density of metabolites in ileum and cecum of AR and HR broiler breeders; the Y axis represented the peak-area (log 10), and the $\mathrm{X}$ axis represented each groups. b: volcano diagram showing different metabolites in the ileum of AR and HR birds; the $Y$ axis represents the $\mathrm{p}$-value (-log 10), and the $X$ axis represents the fold change ( $\log 2)$ of metabolites. The size of the spots represent the metabolite VIP value; black spots represent no-different metabolites; red spots represent up-different metabolites. c: heatmap clusering of different metabolites in the ileum of AR and HR broiler breeders. d: KEGG enrichment pathway analysis from different metabolites in ileum of AR and HR broiler breeders; the $Y$ axis represents the enriched pathwat terms, and the $\mathrm{X}$ axis represents the ratio of individual metaboltes to the whole identified metabolites. The size of the spots represents the number of different metaboltes enriched in each pathway, while the color shade of the spot represented the p-value $(-\log 10)$ of each pathway.

\section{Supplementary Files}

This is a list of supplementary files associated with this preprint. Click to download.

- AdditionalFile1.docx

- AdditionalFile2.docx

- Checklist.docx 